\title{
DOI https://doi.org/10.30525/978-9934-26-118-3-15
}

\section{НОВЫЕ СОЦИАЛЬНЫЕ СЕТИ И ЖУРНАЛИСТИКА: АКТУАЛЬНЫЕ ФОРМАТЫ ВЗАИМОДЕЙСТВИЯ}

\author{
Одаренко О. В. \\ стариий преподаватель кафедры журналистики и новых медиа \\ Киевский университет имени Бориса Гринченко \\ г. Киев, Украина
}

В современном мире социальные сети являются важнейшей составляющей процессов коммуникации. Согласно отчету Global Digital 2021 только в 2020 г. суммарно человечество провело в Интернете более 1,3 миллиарда лет. Большая часть этого времени приходится на социальные сети. Во многом именно социальные сети определяют особенности журналистики - начиная от контента и заканчивая взаимодействием с аудиторией и финансированием изданий. В то же время аналитики, как правило, рассматривают «традиционные» социальные сети, такие как Facebook, Instagram и т.д. В этом же контексте продолжают ассоциировать часть аудитории с той или иной социальной сетью. Например, Facebook считается преимущественно «женской» сетью, тогда как мужчины отдают предпочтение Twitter, LinkedIn, YouTube, TikTok, а также Reddit и WhatsApp.

В 2019 - 2021 гг. получили развитие новые социальные сети, потенциально могущие оказать влияние на развитие журналистики. В 2021 г. популярными стали такие платформы, как Clubhouse, с акцентом на голосовые сообщения; Chirp.io., в которой информация передается в формате двухсекундных звуковых фрагментов; Caffeine, позволяющая делать прямые трансляции и мотивирующая пользователей создавать интересный контент, что делает сеть привлекательной для ведения бизнеса; Bookish - платформа, позволяющая искать книги различными способами; Instagram Reels, подразумевающая обмен короткими роликами и использование в видео различных спецэффектов и музыки, что может быть привлекательным для изданий, специализирующихся на тематике моды и красоты; Houseparty, предусматривающая возможность групповых видеочатов, что может быть весьма полезным при организации работы издания и поддержки коммуникации с целевыми аудиториями; Twitter Spaces; Icebergs - платформа, позволяющая собирать данные в различных форматах и объединять их в группы / создавать проекты / развивать креативные инициативы; 
Thumb, предлагающая одобрять или не одобрять тот или иной выбор и гипотетически позволяющая опосредованно бороться с фейками; Medium - площадка для сотрудничества, которая может быть весьма востребована в социальных проектах; Zeen и Glossi, позволяющие создавать цифровые журналы; Highlight - площадка для знакомства с неизвестными людьми, которая гипотетически может быть востребована журналистами-расследователями.

Под новыми социальными сетями будем понимать платформы, работающие с «расширенной» целевой аудиторией (дети, люди пожилого возраста, мигранты), и предлагающие новые, актуальные форматы генерации и монетизации контента. Новые социальные сети плохо освоены журналистами, в силу чего обрастают разнообразными мифами. Рассмотрим возможности новых социальных сетей для развития журналистики на актуальных технологических основаниях.

Новые социальные сети актуализируют аудиальный канал получения информации. Рост популярности Clubhouse, социальной сети, основанной на голосовом сообщении, является своего рода реакцией на «утомление» от визуальности.

Новые социальные сети являются для медиа пространством для экспериментов. Новые социальные сети успешно оперируют актуальным трендом - стремлением аудитории к развлекательному контенту. В иерархии тематических предпочтений новостной контент занимает едва ли четвертое место, тогда как развлекательный - первое уже несколько лет подряд.

Новые социальные сети подразумевают разнообразие контента - от фрик-контента до серьезного экспертного контента. Медиа могут продвигать «нестандартный контент» - юмор в политике, полезные советы (лайфхаки), рассказы об отдельных фактах или даже вовсе «странный» контент (например, сочетание в видео образов человека и животного / птицы). Также журналисты на камеру могут лично рассказывать о новостях. Например, в ТікТок разнообразный и необычный для традиционных медиа контент обусловлен специфическими требованиями этой социальной сети.

Новые социальные сети создают инфоповоды. Например, взрослая аудитория переходит в TikTok. B TikTok ищут героев и, одновременно, TikTok создает инфоповоды.

Новые социальные сети способствуют развитию гражданской журналистики, а также способствует продвижению жсрналисmов. Влияние новых социальных сетей важно рассматривать в контексте «теории поколений». Новые социальные сети - отличный способ привлечения молодой аудитории. Расширение пользовательской 62 
аудитории Интернета (дети - пожилые люди) привело к вовлечению представителей всех возрастных категорий в процесс генерации контента. Например, именно благодаря ТікТок стала распространенной практика привлечение подростков в качестве журналистов для медиа. С помощью новых социальных сетей можно создать нестандартный образ журналиста; показать «изнанку» редакции или же смешные «неофициальные» фрагменты из репортажей и интервью. Свои аккаунты могут иметь как журналисты, так и отдельные передачи. При этом их популярность может значительно превышать популярность издания в целом.

Новые социальные сети формируют новый язык повествования. Именно это заставляет медиа отказываться от скучных, шаблонных форматов в стиле «журналист в галстуке, и застегнут на все пуговицы». Вполне возможны и уместны трюки с переодеванием, что интригует аудиторию и освежает повествование. К тому же такие приемы способны пробудить интерес к оригинальным или малоизвестным темам. Новые социальные сети являются эффективным инструментом монетизации контента, что важно для электронных медиа, часто пребывающих в поиске источников финансирования.

Новые социальные сети заставляют издания обращать внимание на медиа тренды и особенности потребительского поведения представителей того или другого поколения.

Новые социальные сети тесно связаны с бренд-журналистикой. Например, вполне возможным является продвижение бренда медиа через ТікТок. Но, для медиа должны быть важны показатели успешности в новых социальных сетях. Новые социальные сети - эффективные площадки для рекламы медиа. Более того, новые социальные сети формируют новые форматы рекламы, в частности, политической. Такая реклама может строиться, например, на использовании культуры рэпа, мемов или же пранка.

Таким образом, новые социальные сети позитивно влияют как на работу редакций, так и на генерацию контента и взаимодействие с целевой аудиторией. Медиа получают ресурсы для создания модных форматов, понятных и востребованных широкой аудиторией. 